\title{
Nanofilled and/or toughened POM composites produced by water-mediated melt compounding: Structure and mechanical properties
}

\author{
S. Siengchin ${ }^{1}$, J. Karger-Kocsis ${ }^{1}$, R. Thomann ${ }^{2}$ \\ ${ }^{1}$ Institute for Composite Materials (Institut für Verbundwerkstoffe $\mathrm{GmbH}$ ), University of Kaiserslautern, \\ Erwin-Schrödinger-Str. 58, D-67663 Kaiserslautern, Germany \\ 2Institut für Makromolekulare Chemie und Freiburger Materialforschungszentrum, Albert-Ludwigs-Universität Freiburg, \\ Stefan-Meier-Str. 31, D-79104 Freiburg, Germany
}

Received 16 August 2008; accepted in revised form 18 September 2008

\begin{abstract}
Binary and ternary composites composed of polyoxymethylene (POM), polyurethane (PU) and synthetic boehmite alumina $(\mathrm{AlO}(\mathrm{OH}))$ were produced by water-mediated melt compounding technique. PU latex and/or aqueous alumina suspension were injected into the molten POM in a twin-screw extruder to prepare toughened and/or reinforced polymer composites. The dispersion of the alumina and PU was studied by transmission- and scanning electron microcopy techniques (TEM and SEM, respectively), and discussed. The crystallization of the POM-based systems was inspected by polarized optical microscopy (PLM). The mechanical and thermomechanical properties of the composites were determined in dynamic-mechanical thermal analysis (DMTA), short-time creep tests (performed at various temperatures), uniaxial static tensile and notched Charpy impact tests. Incorporation of alumina increased the stiffness and resistance to creep and reduced the tensile strength, elongation at break and impact toughness. The change in the above parameters was opposite for the POM/PU binary blends. Additional incorporation of alumina in the POM/PU blend enhanced the resistance to creep, elongation at break and maintained the impact toughness compared to the POM/PU blend.
\end{abstract}

Keywords: polymer composites, polymer blends and alloys, processing technologies, mechanical properties, polyoxymethylene (POM)

\section{Introduction}

Nanotechnology is now recognized as one of the most promising areas for technological development in the $21^{\text {st }}$ century. The development of polymer nanocomposites is rapidly emerging fuelled by potential applications in different industry sectors. Nanocomposites belong to class of composites containing dispersed particles in the nanometer range (at least in one dimension). In the related area thermoplastic polymer-based nanocomposites have attracted considerable interest because they often exhibit remarkable property improvements when compared with those of neat polymers or conventional microcomposites.

To prepare thermoplastic polymer nanocomposites different methods have been followed, such as insitu polymerization, melt blending and solution/ dispersion techniques (e.g. [1]). It was early noticed that the preparation technique of the nanocomposites has a strong impact on the dispersion of the nanoparticles. The use of conventional melt compounding techniques to prepare nanocomposites is usually more practical and economical than in situ polymerization. For that purpose common polymer

*Corresponding author, e-mail: karger@pt.bme.hu

(C) BME-PT and GTE 
processing equipments, such as extruders and internal mixers are well suited. The shear forces, accommodated in the melt during processing may also be helpful to support the dispersion of the filler. However, melt shearing is not always enough to break up large agglomerates and thus the resulting filler dispersion may remain further on poor. An alternative way to prepare composite materials is the latex polymerization and compounding (e.g. [2-4]). Latex compounding is a promising route compared, for example, to in-situ polymerization and solution techniques. It is becoming more and more important because of the following benefits. First, many polymers are available in latex form. Second, latex can be introduced in the polymer melt during compounding on line. Note that in an aqueous polymer latex submicron-sized solid polymer particles are suspended in water. When combined with nanosized fillers, the polymer particles and the filler may create a peculiar segregated network. The corresponding material, after drying and 'hot compaction', may show excellent properties at very low filler concentration [3-6] compared to a melt blended version containing the same polymer and filler. The advantage of this latex compounding process is that the expensive chemical modification of the fillers can be avoided if the filler is itself water swellable or dispersible [7]. Moreover, a polymer latex containing well dispersed nanoparticles can be used as a masterbatch (in both dry and liquid forms) for subsequent melt compounding.

Among the water dispersible commercially available nanofillers, natural and synthetic layered silicates, carbon nanotubes, boehmite alumina $(\mathrm{AlO}(\mathrm{OH}))$, should be mentioned [7]. To produce nanocomposites using aqueous dispersions, slurries is not only an affordable method (no organophilic modification is needed for the fillers) but associated also with reduced health hazard. Indeed, the particles when introduced are in micron range and become nano-scaled only in the aqueous media. In the follow-up steps (coagulation, drying etc.) the nanoparticles are already embedded in the polymer which guarantees easy handling and minimized health risk.

Water-mediated melt compounding techniques to disperse various nano- and microfillers were already tried for various thermoplastic systems, such as polypropylene and clay [8], low density polyethylene and cellulose [9]. However, the use of latices to produce nanofiller containing masterbatches for subsequent melt compounding has received far less attention up to now $[10,11]$.

The present work addresses the toughening and reinforcement of polyoxymethylene (POM) via a water-mediated melt compounding technique which allows producing nanocomposites with additional toughening. It is noteworthy that thermoplastic polymers having low resistance to hygrothermal decomposition, like linear polyesters, are not suited for WM-CT. On the other hand, POM is fairly stable against hydrolysis and at the same time requires relatively low processing temperatures. Polyurethane (PU) was selected as toughening agent for POM according to the state-of-art (e.g. [12, 13]). It was used in its latex form. It is noteworthy that the mean size of rubber latices is closely matched with that of conventional toughening agents, impact modifiers. Synthetic boehmite alumina was used as nanofiller. One of the criteria for selecting this filler was that it is water dispersible and thus its nanoscale dispersion can be achieved also in aqueous polymer latex. On the other hand, it was reported that this boehmite alumina can be well dispersed by melt compounding without water as carrier, as well [14].

\section{Experimental}

\subsection{Materials and preparation of composites}

Water dispersible boehmite alumina $(\mathrm{AlO}(\mathrm{OH}))$; Dispal ${ }^{\circledR 11 N 7-80}$ of Sasol GmbH, Hamburg, Germany) served as filler. Its characteristics are as follow: $\mathrm{Al}_{2} \mathrm{O}_{3}$ content: $80 \mathrm{wt} \%$, specific surface area: $100 \mathrm{~m}^{2} / \mathrm{g}$, mean dispersed particle size in water: $220 \mathrm{~nm}$. PU latex with $50 \mathrm{wt} \%$ dry content (Acralen U 550) which has the particles in the size range 100 to $1000 \mathrm{~nm}$ (according to suppliers' information), was kindly supplied by Polymer Latex GmbH (Marl, Germany). Granulated POM (Hostaform C 9021, Ticona GmbH, Frankfurt, Germany) was utilized as polymeric matrix for all composite systems. Its volumetric melt flow rate (MVR at $190^{\circ} \mathrm{C} / 2.16 \mathrm{~kg}$ ) was $8 \mathrm{~cm}^{3} / 10 \mathrm{~min}$.

$\mathrm{POM} / \mathrm{PU}, \mathrm{POM} /$ alumina binary and POM/PU/alumina ternary nanocomposites were prepared by water mediated-continuous technique (WM-CT) in a twin-screw extruder. For the compounding of the composites a special mixing screw of the co-rotating ZSK 25 P8 extruder (Werner \& Pfleiderer, 


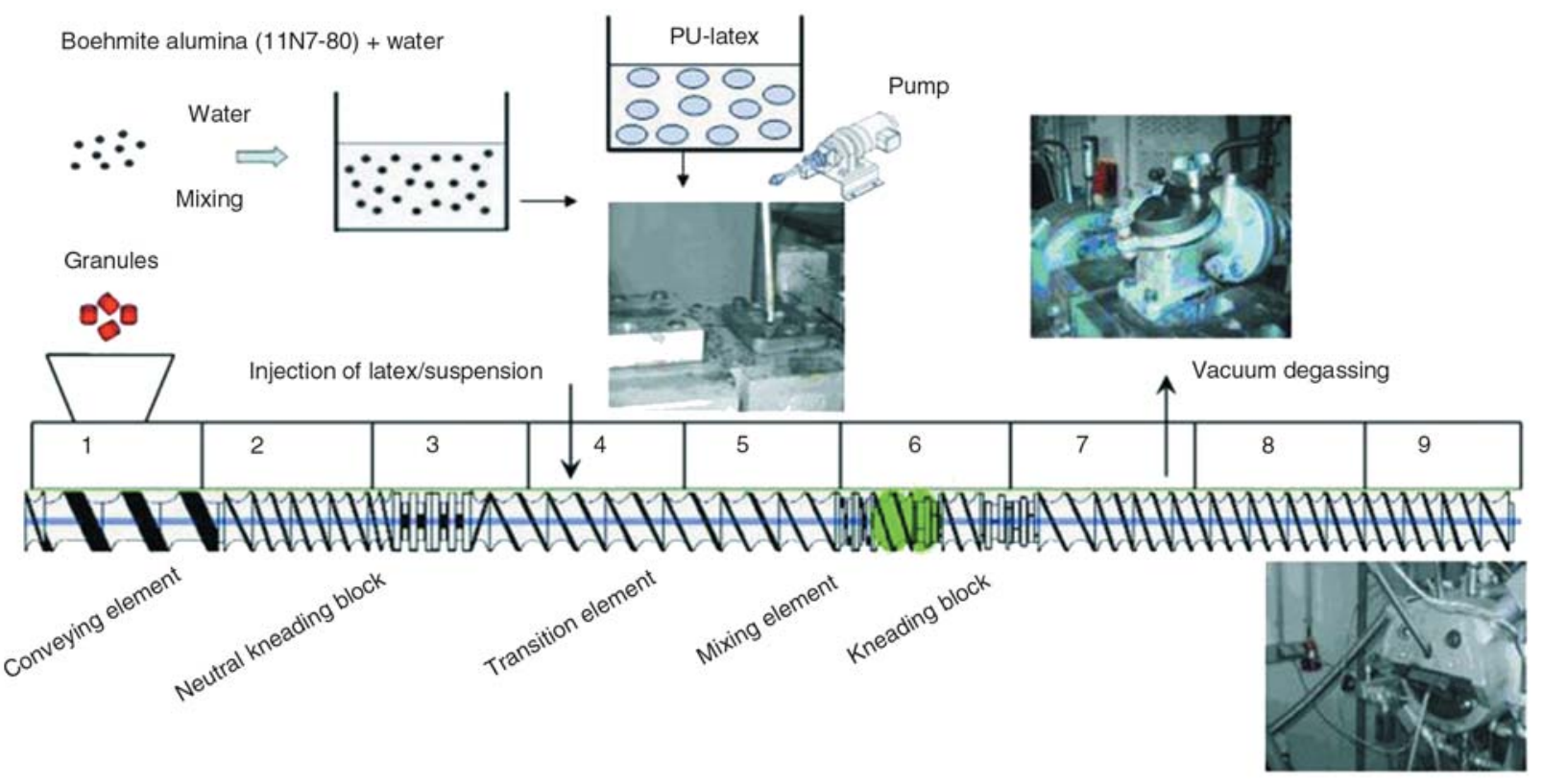

Figure 1. Screw configuration and barrel sections of the corotating twin-screw extruder used

Table 1. Recipe and designation of the POM-based systems

\begin{tabular}{|l|c|c|}
\hline \multicolumn{1}{|c|}{ Sample designation } & $\begin{array}{c}\text { PU content } \\
{[\mathbf{w t} \%]}\end{array}$ & $\begin{array}{c}\text { 11N7-80 alumina } \\
\text { content [wt \%] }\end{array}$ \\
\hline POM & - & - \\
\hline POM/PU(10) & 10 & - \\
\hline $\mathrm{POM} / 11 \mathrm{~N} 7-80(3)$ & - & 3 \\
\hline $\mathrm{POM} / \mathrm{PU}(10) / 11 \mathrm{~N} 7-80(3)$ & 10 & 3 \\
\hline
\end{tabular}

Stuttgart, Germany) was used. The design of the screw with a length-to-diameter ratio of 36 is given in Figure 1.

The alumina particles were dispersed in water at ambient temperature under continuous mechanical stirring for 30 minutes to obtain an aqueous alumina slurry, in which the alumina content was $30 \mathrm{wt} \%$. The rubber particle and/or alumina contents in the binary and ternary composites were set for 10 and $3 \mathrm{wt} \%$, respectively. The POM based composites were compounded at an output rate of ca. $10 \mathrm{~kg} / \mathrm{h}$ by setting the barrel temperatures between 150 (section 1 ) and $190^{\circ} \mathrm{C}$ (from section 2 to 9 according to Figure 1). PU latex and aqueous alumina slurry were injected into the extruder at a rate of $21 / \mathrm{h}, 1 \mathrm{l} / \mathrm{h}$, respectively, using one (binary composites) or two pumps (ternary composites). Type of the pumps was Nemo ${ }^{\circledR}$ Pumpe (Netzsch, Waldkraiburg, Germany). The composites produced are listed in Table 1.

\section{Injection molding process}

The granulated materials were injection molded into standard dumbbell-shaped specimens $(160 \times$ $10 \times 4 \mathrm{~mm}^{3}$ length $\times$ width $\times$ thickness, according to the DIN-ISO-527 standard) by an automatic injection molding machine (Alburg Allrounder 320S, Lossburg, Germany). The barrel temperature of the injection molding machine was set at $200^{\circ} \mathrm{C}$ and that of the mold at $90^{\circ} \mathrm{C}$. The injection pressure was kept constant (700 bar) and for the injection speed of $55 \mathrm{~cm}^{3} / \mathrm{s}$ was selected. For the cooling time $20 \mathrm{~s}$ was chosen.

\subsection{Characterization and testing}

\subsubsection{Morphology detection}

The dispersion of alumina in the POM nanocomposites was studied by transmission and scanning electron microscopy techniques (TEM and SEM, respectively). TEM measurements were carried out with a Zeiss LEO 912 Omega transmission electron microscopic (Oberkochen, Germany) applying an acceleration voltage of $120 \mathrm{kV}$. Thin sections (ca. $50 \mathrm{~nm}$ ) were cut at room temperature with a Diatome diamond knife (Hatfield, PA, USA) using an Ultracut $\mathrm{E}$ microtome (Reichert and Jung, Vienna, Austria).

The fracture surfaces of tensile loaded specimens were subjected to SEM inspection in a Supra ${ }^{\mathrm{TM}}$ 40VP SEM (Carl Zeiss GmbH, Oberkochen, Ger- 
many). The surface was carbon coated prior to SEM inspection performed at low acceleration voltage $(3 \mathrm{kV})$.

\subsubsection{Crystallization and melting properties}

The spherulite growth was observed by polarized light microscopy (PLM). Samples were isothermally crystallized in a hot stage (THMS 600/S, Raczek Analysentechnik, Wedemark, Germany). Thin films of the materials with a thickness of 20-30 microns were used. The film was melted at $200^{\circ} \mathrm{C}$ for $1 \mathrm{~min}$ and then cooled to the isothermal crystallization temperature $\left(T=148^{\circ} \mathrm{C}\right)$ where it was hold for $60 \mathrm{~min}$.

\subsubsection{Thermo-mechanical properties}

Dynamic mechanical analysis (DMA) was made in tensile mode at $1 \mathrm{~Hz}$ frequency using a DMA Q800 apparatus (TA Instruments, New Castle, NJ, USA). The storage- and loss moduli $\left(E^{\prime}, E^{\prime \prime}\right)$ along with mechanical loss factor $(\tan \delta)$ were determined as a function of the temperature $\left(T=-100 \ldots+150^{\circ} \mathrm{C}\right)$. The strain applied was $0.1 \%$ and the heating rate

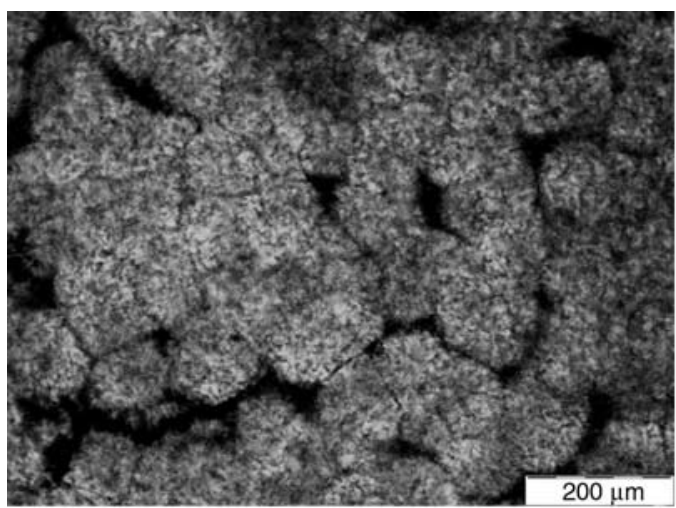

a)

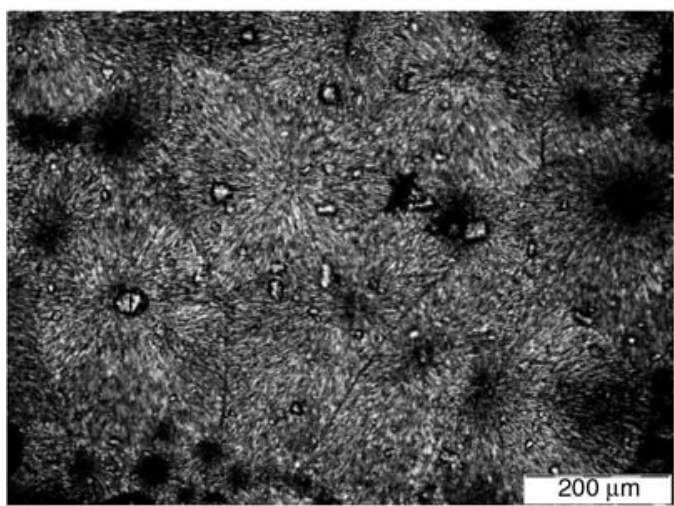

c) was set for $3^{\circ} \mathrm{C} / \mathrm{min}$. The specimen was a dumbbell-shaped type (S3A according to DIN 53504).

\subsubsection{Mechanical response}

Short time creep tests were made in tensile mode at different temperatures using the above DMA apparatus. The creep compliance were determined as a function of the time $\left(t_{\text {creep }}=60 \mathrm{~min}\right)$. The applied tensile stress was $6 \mathrm{MPa}$ (at $0.35 \%$ strain). This was derived from a test series checking the presence of linear isochronous deformation. The creep tests were performed on dumbbell-shaped specimens (5B type according to DIN-EN ISO 527) by considering their rectangular section.

The temperature dependence of the creep response of the POM and its composites was studied in the range from -50 to $80^{\circ} \mathrm{C}$. Isothermal tests were run on the same specimen in the above temperature range by increasing the temperature stepwise by $5^{\circ} \mathrm{C}$ and equilibrating the specimen at each temperature for $5 \mathrm{~min}$. During the isothermal tests the duration of the creep testing was $15 \mathrm{~min}$.

Tensile tests were performed on dumbbell-shaped specimens (DIN-ISO-527) on a Zwick 1474 (Ulm,

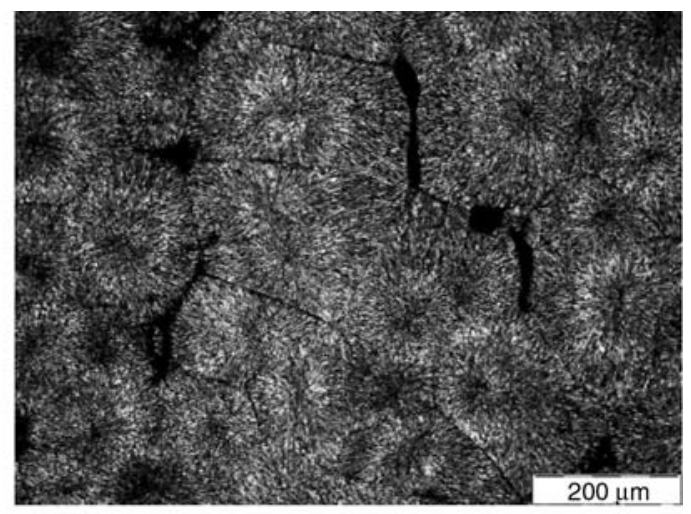

b)

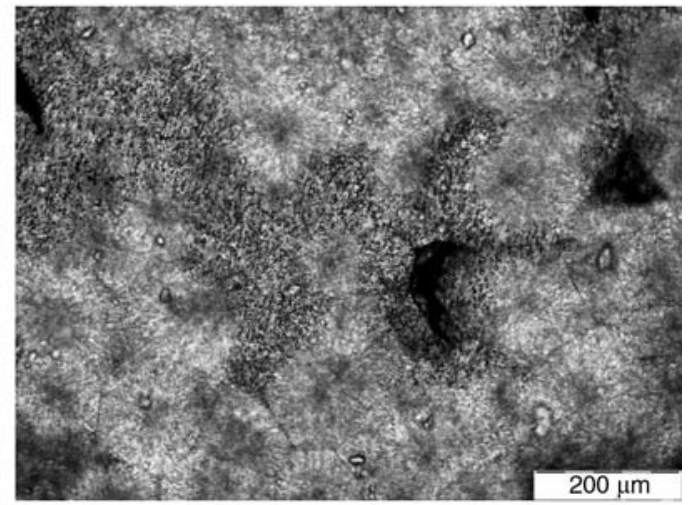

d)

Figure 2. PLM pictures taken of the isothermally crystallized POM (a), POM/PU blend (b), POM/alumina (c) and $\mathrm{POM} / \mathrm{PU} /$ alumina composites (d) 
Germany) universal testing machine. Tests were run at room temperature at $v=2 \mathrm{~mm} / \mathrm{min}$ crosshead speed and the related stress-strain curves were registered.

Impact tests were performed on an instrumented impact tester (AFS-MK4 fractoscope of Ceast, Torino, Italy) according to the standard ISO 179. Striker energy of $4 \mathrm{~J}$, acquisition time of $4 \sim 8 \mathrm{~ms}$, and incident impact velocity of $2.9 \mathrm{~m} / \mathrm{s}$ were set. The specimens were notched rectangular bars $\left(80 \times 10 \times 4 \mathrm{~mm}^{3}\right.$, length $\times$ width $\times$ thickness $)$ with a notch depth of $1 \mathrm{~mm}$ (notch tip radius $0.1 \mathrm{~mm}$ ). Measurements were run at ambient temperature on at least six specimens.

\section{Results and discussion}

\subsection{Morphology detection}

Figures $2 \mathrm{a}-2 \mathrm{~d}$ compare the spherulitic structures of $\mathrm{POM}, \mathrm{POM} / \mathrm{PU}$ blend, POM/alumina binary and

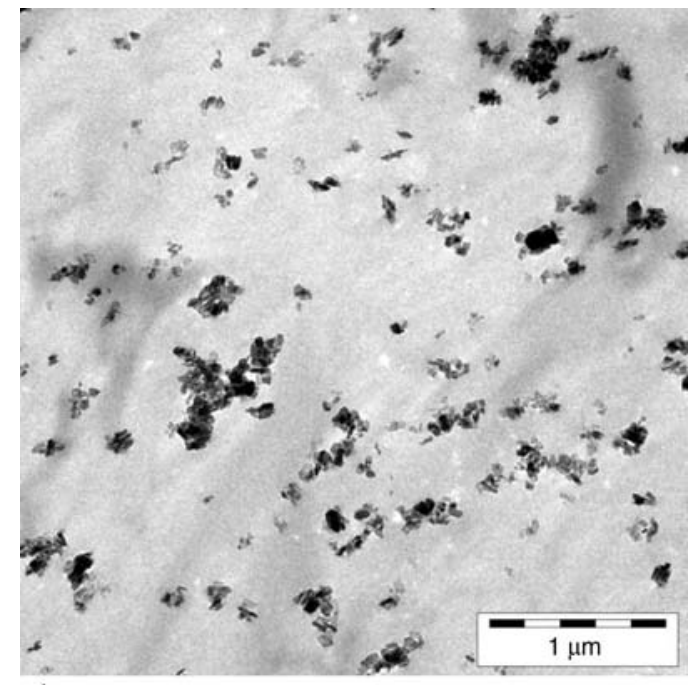

a)

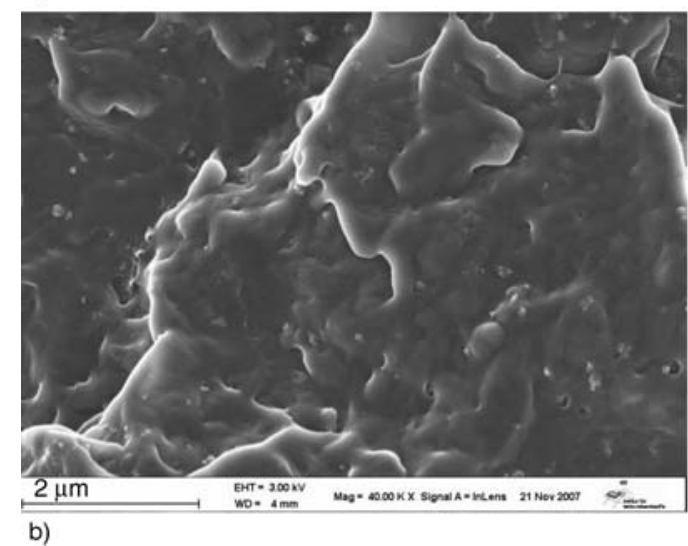

Figure 3. Dispersion of alumina in the POM/alumina composite based on TEM (a) and SEM (b) investigations
POM/PU/alumina ternary composites produced by WM-CT. The spherulite size of POM does not change much with the composition. On the other hand, the build-up of spherulites becomes disturbed by adding PU. Considering additional differential scanning calorimetric results (not reported here) one can conclude that the crystalline structure of POM was not changed by incorporating the alumina slurry or PU latex via the water-mediated technique used.

TEM and SEM pictures taken of the POM/alumina composites, $\mathrm{POM} / \mathrm{PU}$ blend and $\mathrm{POM} / \mathrm{PU} /$ alumina ternary composites are shown in Figures 3, 4 and 5, respectively. SEM pictures taken from the fracture surfaces of tensile loaded specimens give further insight in the dispersion state of the alumina and PU. This is due to the larger view-field in SEM compared to TEM. Figures $3 \mathrm{a}$ and $3 \mathrm{~b}$ show that the alumina particles are nanoscaled and homogeneously dispersed in the matrix, in fact. Figures $4 \mathrm{a}$ and $4 \mathrm{~b}$ demonstrate that the PU rubber particles are
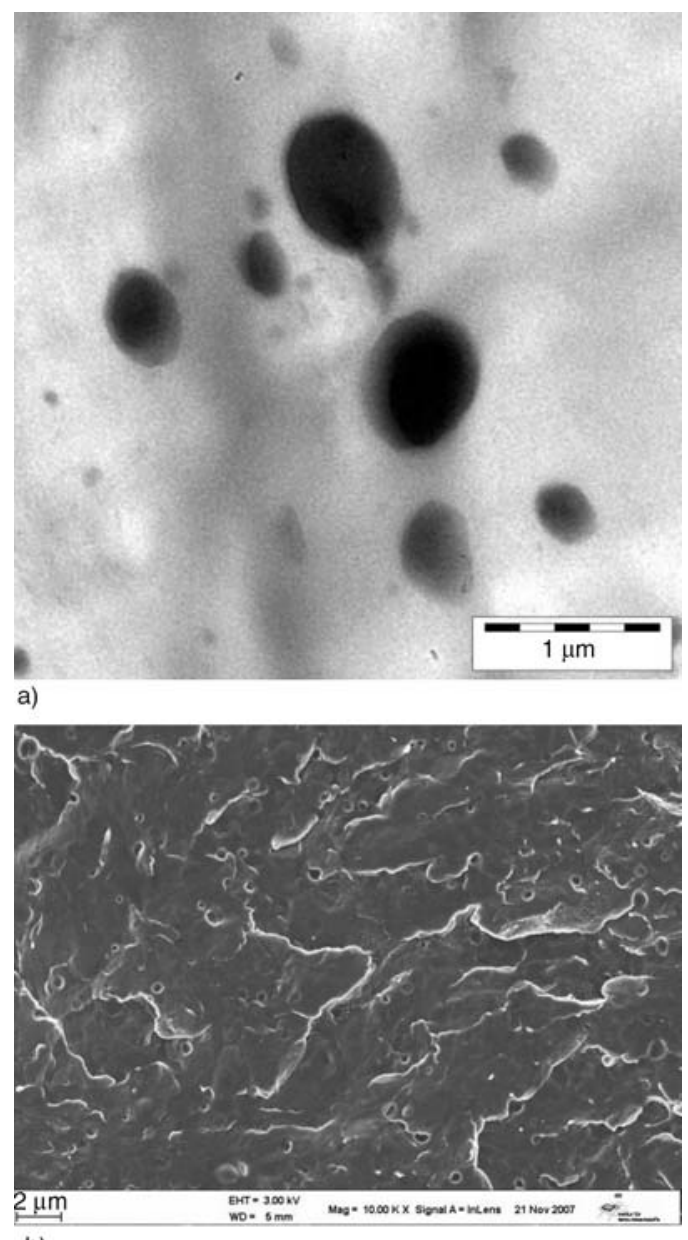

b)

Figure 4. Dispersion of PU in the POM/PU blend based on TEM (a) and SEM (b) investigations 


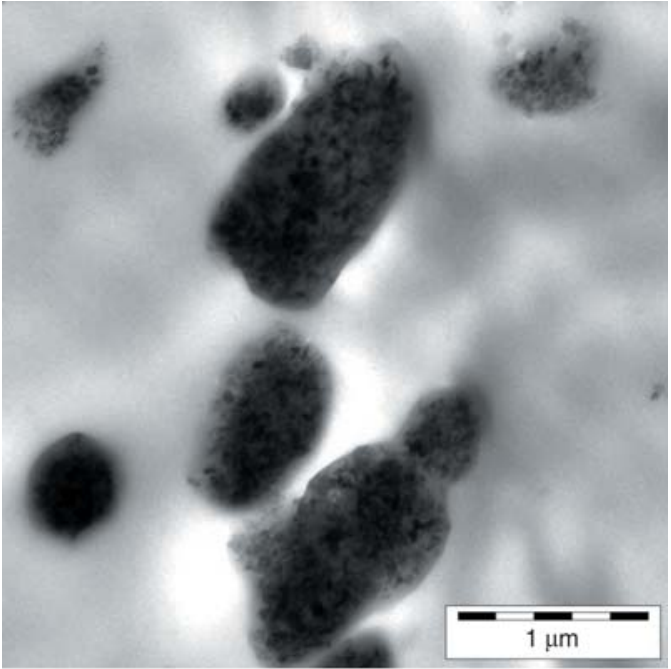

a)

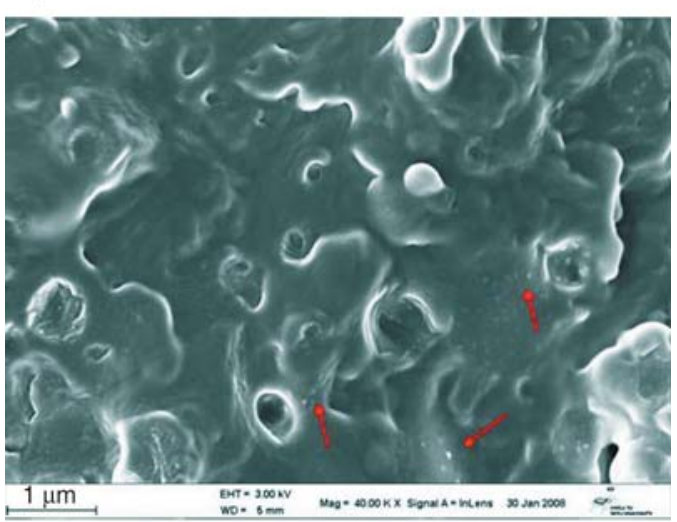

b)

Figure 5. Dispersion of PU and alumina in the POM/PU/ alumina system based on TEM (a) and SEM (b) investigations

also well dispersed in the POM matrix. The mean diameter of the PU is between 700 and $900 \mathrm{~nm}$, which is closely matched with the initial size of the PU particles in the corresponding latex. The above mentioned results support the effective dispersion of the alumina and rubber particles in nanoscale range using the WM-CT. Note that the dispersed PU particle size in a POM/PU blend produced discontinuously was clearly larger compared to the present on-line technique [15]. In the POM/PU/alumina ternary composites (cf. Figure 5a) the alumina particles are mainly in the PU phase. On the other hand, dispersed alumina particles can also be found in the POM matrix based on SEM (cf. particles indicted by arrows in Figure 5b).

\subsection{DMTA response}

The storage modulus $\left(E^{\prime}\right), \tan \delta$ and loss modulus $\left(E^{\prime \prime}\right)$ as a function of temperature are shown for the
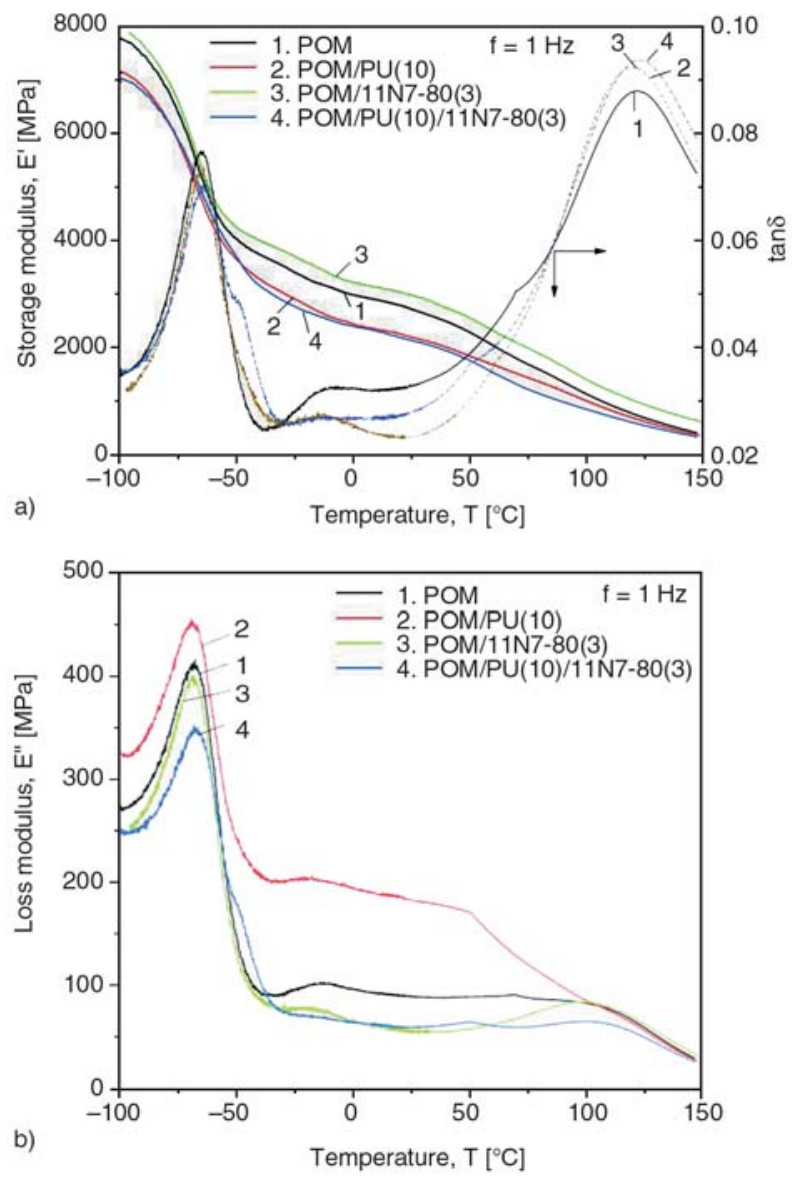

Figure 6. $E^{\prime}$ and $\tan \delta$ vs. $T$ (a) and $E^{\prime \prime}$ vs. $T$ (b) traces for the POM systems prepared by WM-CT

systems studied in Figures $6 a$ and $6 \mathrm{~b}$, respectively. It can be seen from Figure $6 a$ that the modulus $E^{\prime}$ of POM systems decreases with increasing temperature and the stiffness of the POM/PU blend was lower than the POM. However, the incorporation of alumina particles resulted in some increase in the storage modulus in the whole temperature range, compared to that of the pure POM. This can be well explained by reinforcing effect of alumina particles leading to an increased stiffness. Figure $6 \mathrm{~b}$ also shows that the blend containing $10 \mathrm{wt} \%$ of PU exhibits markedly higher loss modulus than the other systems. This is due to the rubbery character of the incorporated PU.

\subsection{Creep behavior}

\section{Short-term creep}

Figures 7 displays the traces of the creep compliance and its simulated value using the Burgers model (e.g. [16-18]), as a function of time at $T=$ $30^{\circ} \mathrm{C}$ for the POM, POM/alumina composite, 


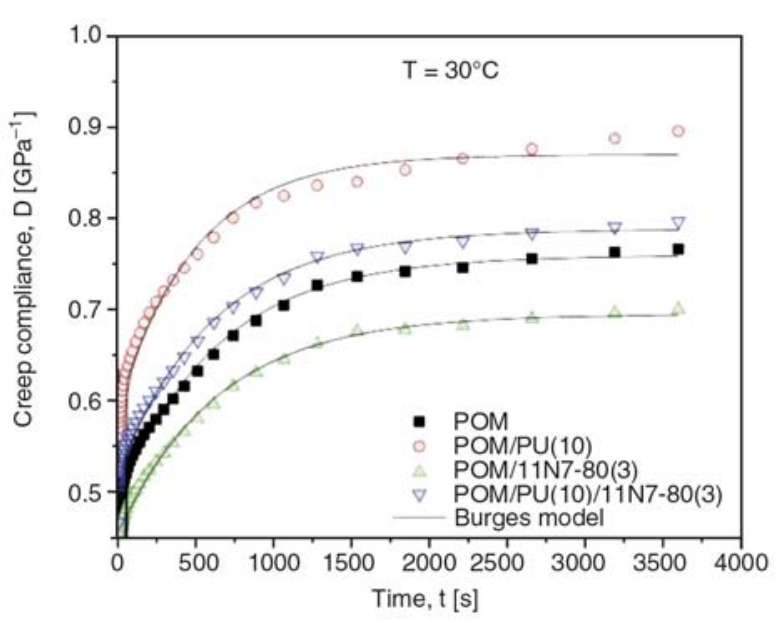

Figure 7. Tensile creep of POM, POM/PU blend, POM/ alumina- and POM/PU/alumina composites at $T=30^{\circ} \mathrm{C}(6 \mathrm{MPa}$ stress applied for $t=60 \mathrm{~min})$. Experimental data were fitted by the Burgers model (see solid lines).

$\mathrm{POM} / \mathrm{PU}$ blend and the alumina-containing ternary composites produced by WM-CT. The incorporation of alumina particles into POM matrix resulted in a considerable decrease of the creep compliance, as expected owing to their reinforcing effect. Conversely, the addition of PU increased the creep of POM. The compliance values were reduced by approx. $12 \%$ compared to the POM/PU blend when alumina was additionally incorporated. This creep response suggests again that alumina particles may be dispersed also in the POM matrix. This was supported by the SEM inspection (cf. Figure 5b). Parameters of the Burgers model were determined for each curve using the related software package of the DMTA device (Rheology Advantage Data Analysis) and listed in Table 2. The Burgers model consists of Maxwell and Voigt-Kelvin units con- nected in series. This phenomenological model was used to evaluate the effect of rubber and/or alumina particles on the instantaneous $\left(D_{0}\right)$ and equilibrium $\Psi(t)$ parts (that was approximated by six VoigtKelvin elements) of the creep compliance $(D(t))$ determined by the Equations (1) and (2) [16]:

$$
\begin{aligned}
& D(t)=D_{0}+\Psi(t)+\frac{t}{\mu_{0}} \\
& \Psi(t)=\sum_{k=1}^{N} D_{k} \cdot\left(1-e^{\frac{-t}{\tau_{k}}}\right)
\end{aligned}
$$

where $t$ is the time, $D_{0}$ is the instantaneous compliance, $\Psi(t)$ is equilibrium compliance part of creep compliance, $\mu_{0}$ is the viscosity and $\tau_{k}$ denotes the retardation time of the Voigt-Kelvin unit $D_{k}$.

The highest instantaneous compliance $\left(D_{0}\right)$ was observed when PU was added into the POM. As shown in Table 2, one can see that the instantaneous compliance of the POM/alumina composite is lower than those of the POM and POM/PU blend. The enhancement in the instantaneous part of compliance is caused by the alumina particles and their dispersed state. This resulted in a decrease in the mobility of the amorphous segments.

Figures 8a-8d, demonstrate the effects of increased temperature on the creep response of $\mathrm{POM}, \mathrm{POM} /$ $\mathrm{PU}$ blend, POM/alumina binary- and POM/PU/alumina ternary composites. The creep of all POM systems is sensitive to the temperature. A more interesting observation is the relative change in the transient creep with respect to instantaneous creep as the temperature increases. Unlike to pure POM,

\begin{tabular}{|c|c|c|c|c|c|}
\hline Temperature & Parameter & POM & POM/PU(10) & POM/11N7-80(3) & POM/PU(10)/11N7-80(3) \\
\hline \multirow{14}{*}{$30^{\circ} \mathrm{C}$} & $D_{0}\left[\mathrm{~Pa}^{-1}\right]$ & $3.63 \cdot 10^{-10}$ & $3.77 \cdot 10^{-10}$ & $2.58 \cdot 10^{-10}$ & $1.39 \cdot 10^{-11}$ \\
\hline & $D_{k 1}\left[\mathrm{~Pa}^{-1}\right]$ & $2.22 \cdot 10^{-10}$ & $2.15 \cdot 10^{-10}$ & $2.26 \cdot 10^{-10}$ & $2.39 \cdot 10^{-10}$ \\
\hline & $\tau_{1}[\mathrm{~s}]$ & 626 & 451.6 & 690.3 & 615.6 \\
\hline & $D_{k 2}\left[\mathrm{~Pa}^{-1}\right]$ & $4.01 \cdot 10^{-11}$ & $5.92 \cdot 10^{-11}$ & $5.66 \cdot 10^{-11}$ & $7.41 \cdot 10^{-11}$ \\
\hline & $\tau_{2}[\mathrm{~s}]$ & 24.38 & 17.83 & 9.52 & 7.34 \\
\hline & $D_{k 3}\left[\mathrm{~Pa}^{-1}\right]$ & $7.61 \cdot 10^{-12}$ & $4.24 \cdot 10^{-12}$ & $1.09 \cdot 10^{-11}$ & $3.72 \cdot 10^{-10}$ \\
\hline & $\tau_{3}[\mathrm{~s}]$ & 0.15 & 4.19 & 0.22 & 0.04 \\
\hline & $D_{k 4}\left[\mathrm{~Pa}^{-1}\right]$ & $1.29 \cdot 10^{-15}$ & $2.52 \cdot 10^{-15}$ & $2.09 \cdot 10^{-11}$ & $2.56 \cdot 10^{-15}$ \\
\hline & $\tau_{4}[\mathrm{~s}]$ & 0.51 & 5.31 & 6.33 & 0.15 \\
\hline & $D_{k 5}\left[\mathrm{~Pa}^{-1}\right]$ & $8.63 \cdot 10^{-11}$ & $1.41 \cdot 10^{-10}$ & $3.16 \cdot 10^{-11}$ & $6.98 \cdot 10^{-11}$ \\
\hline & $\tau_{5}[\mathrm{~s}]$ & 1.77 & 1.47 & 0.07 & 0.02 \\
\hline & $D_{k 6}\left[\mathrm{~Pa}^{-1}\right]$ & $9.09 \cdot 10^{-12}$ & $2.89 \cdot 10^{-11}$ & $8.53 \cdot 10^{-11}$ & $5.42 \cdot 10^{-15}$ \\
\hline & $\tau_{6}[\mathrm{~s}]$ & 0.11 & 0.32 & 0.28 & 0.005 \\
\hline & $\mu_{0}[\mathrm{~Pa} \cdot \mathrm{s}]$ & $8.25 \cdot 10^{13}$ & $5.41 \cdot 10^{13}$ & $3.68 \cdot 10^{14}$ & $1.38 \cdot 10^{14}$ \\
\hline
\end{tabular}

Table 2. Burgers parameters for the creep response of the POM-based systems studied 

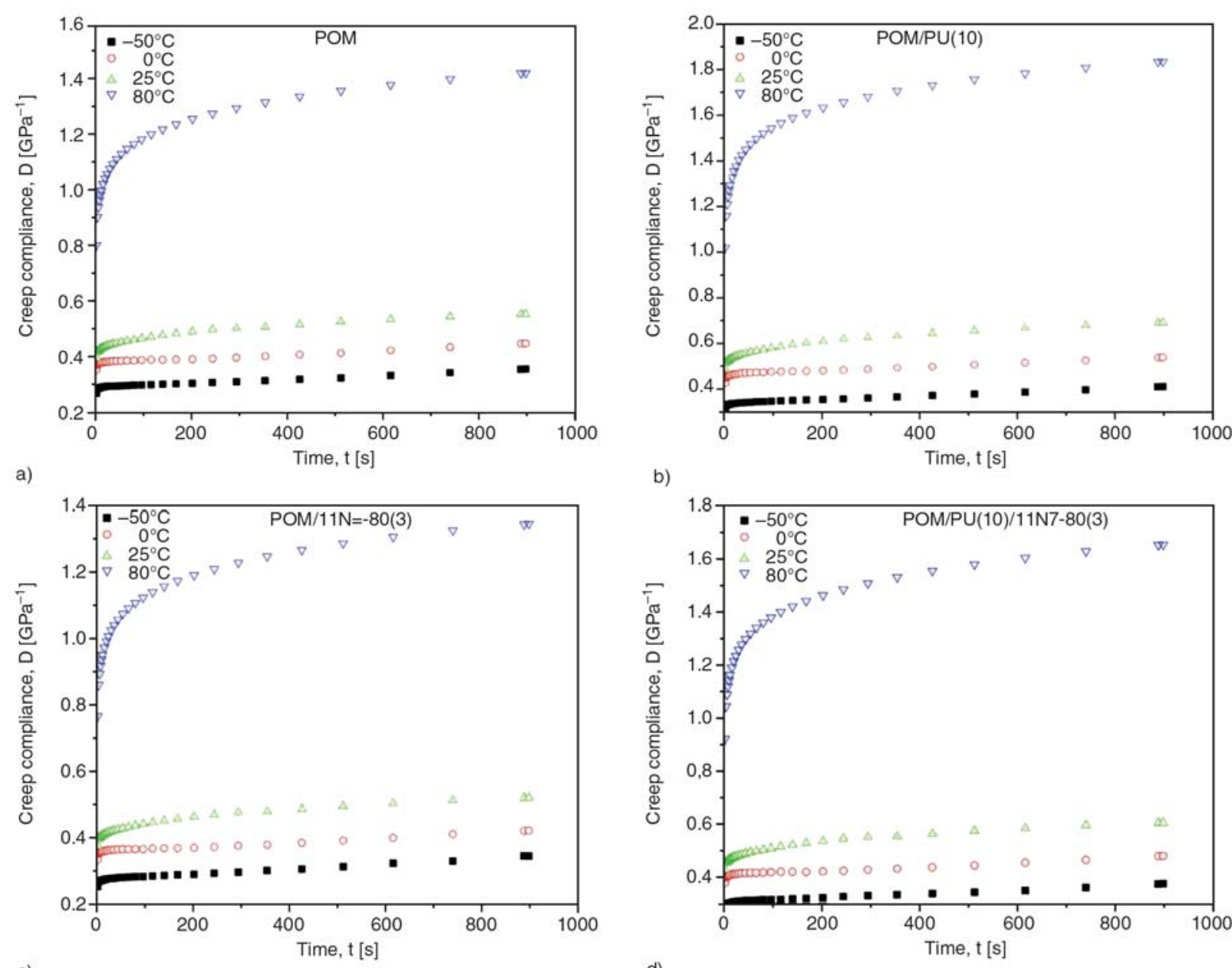
c)

Figure 8. Effect of temperature on the tensile creep of POM (a), POM/PU blend (b) POM/alumina binary composite (c) and POM/PU/alumina ternary composite (d)

the incorporation of $3 \mathrm{wt} \%$ alumina particles reduced the creep compliance significantly, even at elevated temperatures. The creep data, measured in function of both time and temperature $(T=-50 \ldots$ $80^{\circ} \mathrm{C}$ ), have been considered to create creep master curves by adopting the time-temperature superposition (TTS) principle. The creep at other temperatures as measured can be estimated by considering the shift factor $\left(a_{T}\right)$ along the time scale $(t)$ (Equation (3)) :

$$
D\left(t, T_{1}\right)=\frac{D\left(t, T_{2}\right)}{a_{T}}
$$

The shift factors can be also correlated with temperature using the Williams-Landel-Ferry (WLF) (Equation (4)) [17]:

$$
\log \left(a_{T}\right)=\frac{-C_{1} \cdot\left(T-T_{0}\right)}{C_{2}+\left(T-T_{0}\right)}
$$

where $C_{1}$ and $C_{2}$ are constants and $T_{0}$ is the reference temperature $\left(T_{0}=30^{\circ} \mathrm{C}\right)$.

Note that the above description has been employed for many polymeric materials to fit the creep compliance vs. time curves. Figure 9 displays the

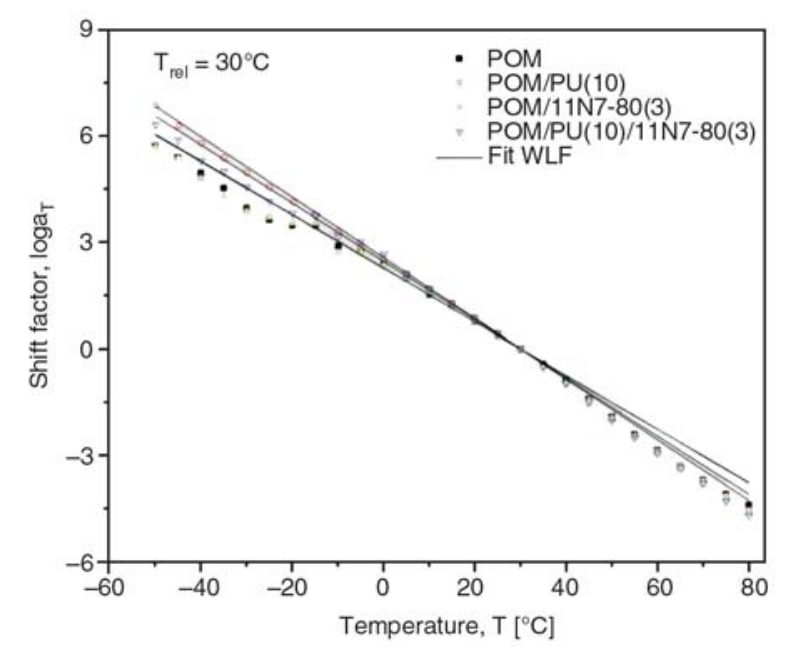

Figure 9. Experimental shift factors of the systems studied along with the related WLF fits 
course of the experimentally determined $a_{T}$ values as a function of the temperature. Master curves were created by using the above mentioned software package of the DMTA device. It has to be mentioned that this software allows only horizontal shifting of the creep curves along the time axis. A reference temperature $\left(T_{0}=30^{\circ} \mathrm{C}\right)$ was used for the superposition process.

An empirical description for the creep compliance vs. time is given by Findley power law (Equation (5)) [18]:

$D_{F}=D_{F 0}+D_{F 1} \cdot t^{n}$

where $n$ is a constant independent of stress, $D_{F 0}$ is the time-independent compliance, and $D_{F 1}$ is the coefficient of the time-dependent term.

Figure 10 shows the constructed master curves along with their Findley fits. The parameters of the Findley power law are listed in Table 3. Incorporation of alumina particles decreased the creep. This was expected based on the reinforcing effect of the nanoscale disperse alumina. By contrast, rubber particles markedly increased the creep. The POM systems experienced prominent creep by the incorporation of $\mathrm{PU}$ for both in POM/PU blend and

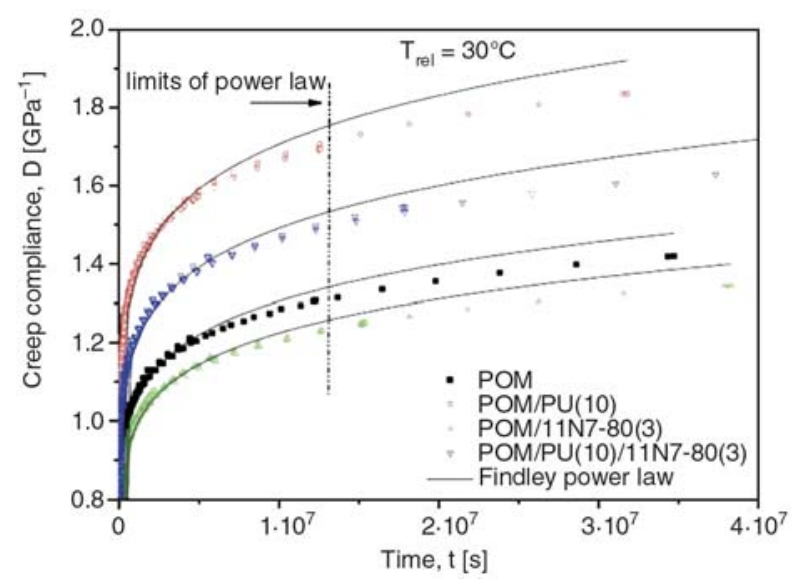

Figure 10. Creep master curves (creep compliance vs. time) constructed by considering $T_{r e f .}=30^{\circ} \mathrm{C}$ for the POM based systems. Note: continuous line represents the Findley fit.

Table 3. Findley parameters for the creep master curves of the POM-based systems studied

\begin{tabular}{|l|c|c|c|}
\hline \multicolumn{1}{|c|}{ Sample designation } & $\begin{array}{c}\mathbf{D}_{\mathbf{F} 0} \\
{\left[\mathbf{G P a}^{-\mathbf{1}}\right]}\end{array}$ & $\begin{array}{c}\mathbf{D}_{\mathbf{F 1}} \\
{\left[\mathbf{G P a}^{\mathbf{- 1}} \cdot \mathbf{s}^{\mathbf{1 / n}}\right]}\end{array}$ & $\mathbf{n}$ \\
\hline POM & 0.26 & 0.14 & 0.122 \\
\hline POM/PU(10) & 0.32 & 0.19 & 0.124 \\
\hline POM/11N7-80(3) & 0.25 & 0.13 & 0.123 \\
\hline POM/PU(10)/11N7-80(3) & 0.28 & 0.17 & 0.124 \\
\hline
\end{tabular}

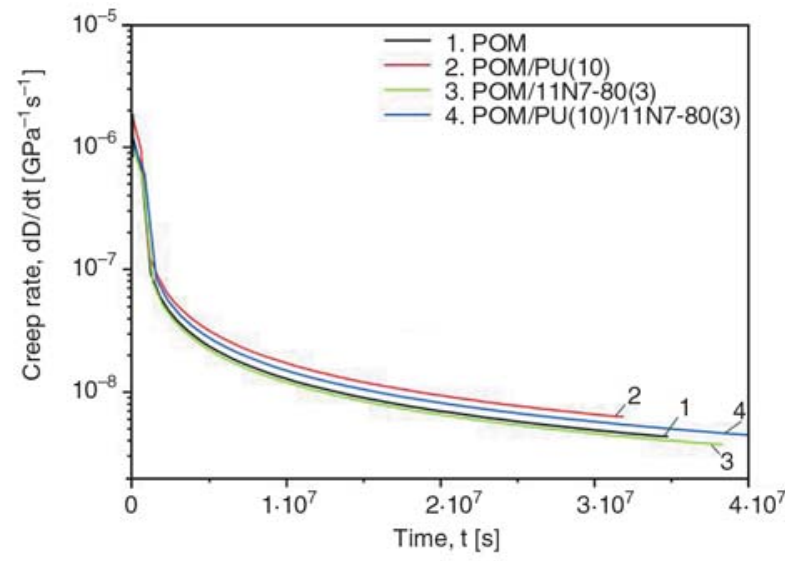

Figure 11. Creep rate as a function of time at $T=30^{\circ} \mathrm{C}$ for the POM systems studied

POM/PU/alumina ternary composite. Figure 10 also shows that the power law model fits very well to the creep data for all system up to 3000 hours or at least until a given threshold. Similar results were reported for a polyamide 6.6 composite containing $\mathrm{TiO}_{2}$ nanoparticles [19]. The authors observed that the power law is in good agreement with the experimental results until a given time, while for longer time duration the calculated data may show considerable deviation from the experimental results. It should be noted that the master curves constructed from short-term creep data at high temperature may not follow the expected creep behavior. This is mostly due to the increasing mobility of the polymer chains.

A creep rate can be quantified as the time derivative $(\mathrm{d} D / \mathrm{d} t)$ of the creep compliance vs. time curves. Figure 11 displays the effect of alumina on the creep rate of POM and POM/PU blend. Note that the creep rate decreases with increasing time and marginally also with the addition of alumina particles. It is also clear from this figure that the presence of rubber particles increase the creep rate of POM matrix.

\subsection{Tensile tests}

Results of the tensile mechanical tests are given in Figure 12. The tensile mechanical and impact data are listed in Table 4. It is clearly seen that the incorporation of alumina and PU particles strongly affected the mechanical behavior of POM. Adding alumina increased the stiffness, slightly reduced the tensile strength, and prominently the elongation at break. Conversely, the ductility of the POM/PU blend increased and the stiffness and strength 
Table 4. Tensile mechanical and impact characteristics of the neat POM, POM/PU blend, POM/alumina binary and POM/PU/alumina ternary composites prepared by WM-CT

\begin{tabular}{|l|c|c|c|c|}
\hline \multicolumn{1}{|c|}{ Sample designation } & $\begin{array}{c}\text { Tensile strength } \\
{[\mathbf{M P a}]}\end{array}$ & $\begin{array}{c}\text { Tensile modulus } \\
{[\mathbf{M P a}]}\end{array}$ & $\begin{array}{c}\text { Elongation at break } \\
{[\%]}\end{array}$ & $\begin{array}{c}\text { Notched Charpy } \\
\text { impact energy }\left[\mathbf{k J} / \mathbf{m}^{2}\right]\end{array}$ \\
\hline POM & $63 \pm 0.2$ & $2646 \pm 71$ & $17.8 \pm 2.8$ & $13.5 \pm 1.1$ \\
\hline POM/PU(10) & $55 \pm 0.2$ & $2392 \pm 101$ & $31.9 \pm 4.5$ & $16.3 \pm 1.3$ \\
\hline POM/11N7-80(3) & $61 \pm 0.1$ & $2847 \pm 143$ & $9.1 \pm 2.8$ & $9.8 \pm 1.5$ \\
\hline POM/PU(10)/11N7-80(3) & $47 \pm 0.5$ & $2323 \pm 62$ & $57.1 \pm 8.0$ & $15.6 \pm 1.1$ \\
\hline
\end{tabular}

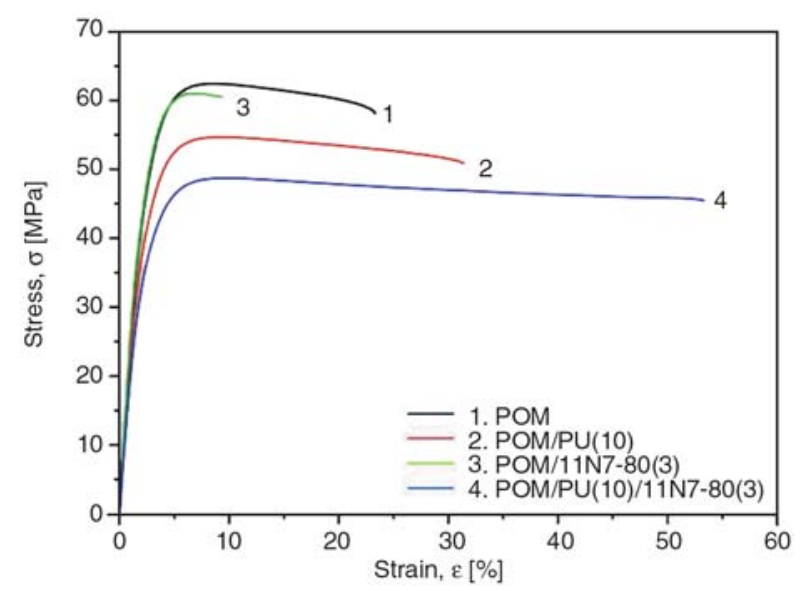

Figure 12. Characteristic tensile stress-strain curves for the POM systems studied

decreased compared to the neat POM. The reduction in the tensile strength may be attributed to the presence of rubber particles acting as stress concentrators and forcing the yielding of POM at lower stresses. The decrease in the tensile modulus in the $\mathrm{POM} / \mathrm{PU}$ blend may be accounted for the softening effect of PU, since the tensile modulus of rubber is considerably lower than that of the neat POM. The POM/PU/alumina ternary composites exhibited significant decrease in modulus accompanied by much higher elongation at break as compared to the $\mathrm{POM}, \mathrm{POM} /$ alumina composite and $\mathrm{POM} / \mathrm{PU}$ blend.

\subsection{Impact properties}

Although the tensile modulus of POM is increased by the incorporation of alumina particles, the toughness was reduced. However, POM modified with $10 \mathrm{wt} \%$ PU exhibited not only higher elongation at break, but simultaneously also higher impact energy ( 22\%) compared to the neat POM (cf. Table 4). This is due to the submicron dispersion of the rubber particles. Accordingly, the incorporation of rubbery particles in a suitable size range increases the impact resistance of POM, as expected.
Furthermore, the impact energy of POM/PU/alumina ternary composites decreased marginally compared to the POM/PU blend but remained still higher than that of POM.

\section{Conclusions}

Toughened or nanofilled POM composites have been successfully produced by WM-CT. SEM and TEM results have shown that the alumina and rubber dispersions became fine and homogeneous when using the water-mediated extrusion melt compounding. The mechanical properties (stiffness and creep resistance) of the binary POM/alumina and ternary $\mathrm{POM} / \mathrm{PU} /$ alumina composites were superior to those of the POM and POM/PU blend, respectively. The impact resistance of POM was highly enhanced by the addition of PU rubber, dispersed in submicron range. The size of the dispersed PU agreed fairly with that of the initial PU latex. Incorporation of PU into POM increased the creep compliance, whereas additional modification with boehmite alumina yielded a reverse effect. The creep resistance of the binary POM/alumina composite was higher than the neat POM. Creep master curves in form of compliance vs. time, constructed by considering short-term creep data, could be well described by the Findley power law model, at least until a given threshold value. The proposed water-mediated extrusion melt compounding is a very effective process being simple and cost efficient for producing thermoplastic nanocomposite with and without additional toughening. A further benefit of this method is that the expensive chemical modification of the nanofillers can be avoided.

\section{Acknowledgements}

S. Siengchin thanks the DFG (German Research Foundation) for the fellowship in the framework of the graduate school GRK 814. POM and alumina were kindly provided 
by Dr. N. Papke (Ticona, Frankfurt, Germany) and Dr. O. Torno (Sasol, Hamburg, Germany), respectively.

\section{References}

[1] Karger-Kocsis J., Zhang Z.: Carbon nanotube and carbon nanofiber-reinforced polymer composites. in 'Mechanical Properties of Polymers Based on Nanostructure and Morphology' (eds.: Michler G. H., Baltá-Calleja F. J.) CRC Press, Boca Raton, 553-602 (2005).

[2] Park E. J., Heo H., Lim K. T.: Synthesis and characterization of $\mathrm{Al}(\mathrm{OH})_{3}$ /polystyrene nanocomposite latex particles by emulsion polymerization. Macromolecular Symposia, 249-250, 247-250 (2007).

[3] Jia Q-X., Wu Y-P., Xu Y-L., Mao H-H., Zhang L-Q.: Combining in-situ organic modification of montmorillonite and the latex compounding method to prepare high-performance rubber-montmorillonite nanocomposites. Macromolecular Materials and Engineering, 291, 218-226 (2006).

[4] Miltner H. E., Grossiord N., Lu K., Loos J., Koning C. E., Van Melle B.: Isotactic polypropylene/carbon nanotube composites prepared by latex technology. Thermal analysis of carbon nanotube-induced nucleation. Macromolecules, 41, 5753-5762 (2008).

[5] Grunlan J. C., Mehrabi A. R., Bannon M. V., Bahr J. L.: Water-based single-walled-nanotube-filled polymer composite with an exceptionally low percolation threshold. Advanced Materials, 16, 150-153 (2004).

[6] Grunlan J. C., Kim Y-S., Ziaee S., Wei X., AbdelMagid B., Tao K.: Thermal and mechanical behavior of carbon nanotube-filled latex. Macromolecular Materials and Engineering, 291, 1035-1043 (2006).

[7] Karger-Kocsis J.: Water-mediated dispersion of 'nanofillers' in thermoplastics: Is it the right way? Express Polymer Letters, 2, 312 (2008).

[8] Kato M., Matsushita M., Fukumori K.: Development of a new production method for a polypropylene-clay nanocomposites. Polymer Engineering and Science, 44, 1205-1211 (2004).
[9] Soulestin J., Quiévy N., Sclavons M., Devaux J.: Polyolefins-biofibre composites: A new way for an industrial production. Polymer Engineering and Science, 47, 467-476 (2007).

[10] Siengchin S., Karger-Kocsis J., Thomann R.: Alumina-filled polystyrene micro- and nanocomposites prepared by melt mixing with and without latex precompounding: Structure and properties. Journal of Applied Polymer Science, 105, 2963-2972 (2007).

[11] Siengchin S., Karger-Kocsis J., Apostolov A., Thomann R.: Polystyrene-fluorohectorite nanocomposites prepared by melt mixing with and without latex precompounding: Structure and mechanical properties. Journal of Applied Polymer Science, 106, 248-254 (2007).

[12] Mehrabzadeh M., Rezaie D.: Impact modification of polyacetal by thermoplastic elastomer polyurethane. Journal of Applied Polymer Science, 84, 2573-2582 (2002).

[13] Gao X., Qu C., Fu Q.: Toughening mechanism in polyoxymethylene/thermoplastic polyurethane blends. Polymer International, 53, 1666-1671 (2004).

[14] Streller R. C., Thomann R., Torno O., Mülhaupt R.: Isotactic poly(propylene) nanocomposites based upon boehmite nanofillers. Macromolecular Materials and Engineering, 293, 218-227 (2008)

[15] Siengchin S., Karger-Kocsis J., Psarras G. C., Thomann R.: Polyoxymethylene/polyurethane/alumina ternary composites: Structure, mechanical, thermal and dielectric properties. Journal of Applied Polymer Science, 110, 1613-1623 (2008).

[16] Kaschta J., Schwarzl F. R.: Calculation of discrete retardation spectra from creep data-I. Method. Rheologica Acta, 33, 517-529 (1994).

[17] Ferry J. D.: Viscoelastic properties of polymers. Wiley, New York (1980).

[18] Findley W. N., Lai J. S., Onaran K.: Creep and relaxation of nonlinear viscoelastic materials. Dover Publications, New York (1989).

[19] Starkova O., Yang J., Zhang Z.: Application of timestress superstition to nonlinear creep of polyamide 66 filled with nanoparticles of various sizes. Composites Science and Technology, 67, 2691-2698 (2007). 